\title{
Tarkkuusviljelyn tiedonkäsittely paikkatietoa hyödyntävässä sääntöpohjaisessa päättelyssä
}

\author{
Raimo Nikkilä1), Ilkka Seilonen ${ }^{2)}$, Jere Kaivosoja ${ }^{3)}$ \\ 1)Automaation tietotekniikka - Aalto-yliopiston sähkötekniikan korkeakoulu, raimo.nikkila@aalto.fi \\ 2)Automaation tietotekniikka - Aalto-yliopiston sähkötekniikan korkeakoulu, ilkka.seilonen@aalto.fi \\ 3)Maa-ja elintarviketalouden tutkimuskeskus, jere.kaivosoja@mtt.fi
}

\section{Tiivistelmä}

Tämä tutkimus keskittyy maatalouskoneiden tarkkuusviljelyn pelto-operaatioista kerätyn paikkatiedon soveltamiseen automaattisessa viljelysäännöstöjen ja rajoitusten valvonnassa. Tämä valvonta edellyttää automaattisen päättelyn lisäksi laaja-alaista tiedonhallintaa sekä tietointegraatiota lukuisten maatalouden tietojärjestelmien välillä.

Tutkimustarkoituksiin on FutureFarm EU-projektissa kehitetty paikkatietoa tukeva konepäättelijä, jolle viljelysäännöstöt ja -rajoitukset esitetään formaalissa tietokonekäsiteltävässä muodossa. Yhteisten esitysmuotojen puute tiedonsiirrossa on kuitenkin merkittävä rajoitus useille maatalouden tietojärjestelmille, etenkin kun tietoa siirretään useamman kuin kahden järjestelmän välillä. Toimiakseen konepäättelijä vaatii viljelysääntöjen lisäksi huomattavan määrän tietoa useista eri lähteistä, joista vain yksi on maatilan oma viljelynhallintajärjestelmä (FMIS). Koska monet viljelysäännöistä ovat luonteltaan paikkoihin ja etäisyyksiin sidottuja, on paikkatiedon käsittely tutkimuksen keskeisimpiä osa-alueita. Sääntöjen esittämiseksi W3C standardoimaan RIF sääntöesityskieleen jouduttiin tekemään paikkatietolaajennuksia.

Viljelysääntöjen automaattinen valvonta osoittautui mahdolliseksi käyttäen apuna edellä mainittua konepäättelijää mutta päättelijän vaatimien tietojen kerääminen ja muuntaminen sopiviin esitysmuotoihin on vaikeaa. Tutkimuksessa käytettiin paikkatiedon esittämiseen XML-pohjaista GML2 esitysmuotoa ja muulle viljelytiedolle Saksalaista AgroXML tiedostomuotoa.

Asiasanat: Viljelysäännöstöt, palveluarkkitehtuuri, tietointegraatio 


\section{Johdanto}

Maatilojen talouden kannalta välttämättömien tukien maksaminen ja lainsäädäntö edellyttävät useiden erilaisten viljelysäännöstöjen noudattamista. Nykyisin huomattava määrä aikaa ja resursseja käytetään näiden viljelysäännöstöjen valvontaan[11, 2]. Tämä valvonta on lisäksi pitkälti manuaalinen prosessi, johon sisältyy enemmän paperisia listoja ja tulosteita, ja vähemmän moderneja tietojärjestelmiä. Tarkkuusviljelyn ohessa kerättävä paikkatieto ja muu viljelytieto mahdollistavat kuitenkin valvontaprosessin automatisoimisen. Pelkästään viljelytiedon saatavuus ei kuitenkaan ole riittävä edellytys tälle automatisoinnille, vaan lisäksi tarvitaan ulkoista paikkatietoa, viljelysäännöstöille konekäsiteltävä esitysmuoto sekä tietointegraatiota lukuisten tietolähteiden välille.

Viljelysäännöstöjen valvonnan automatisoimisen eri osa-alueita on tutkittu eurooppalaisessa FutureFarm projektissa ${ }^{1}$. Osa tämän projektin tuloksista on jo julkaistu tieteellisissä lehdissä sekä konferensseissa $[6,9,7]$. Tämä paperi käsittelee samaa viljelysääntöjen valvonnan automatisoimista mutta tarkkuusviljelyn tiedonkäsittelyn ja tietointegraation näkökulmasta. Paperin erityinen painopiste on paikkatiedon integraatiolla viljelysääntöjä käsittelevässä konepäättelijässä.

\section{Aineisto ja menetelmät}

Tutkimuksessa käytettiin saksalaisia "Düengeverordnung" viljelysäännöstön sääntöjä, jotka esitettiin W3C uudessa Rule Interchange Format (RIF) esitysmuodossa[1]. RIF esitysmuoto ei kuitenkaan sellaisenaan tue paikkatietoa tai paikkatiedon käsittelyä, joten siihen tehtiin muutamia paikkatietokohtaisia laajennuksia ja lopputulos sai nimen GeoRIF[5]. GeoRIF on RIF esitysmuodon puhdas laajennus, eli jokainen RIF dokumentti on myös GeoRIF dokumentti. Käytännön esimerkki tästä esitysmuodosta löytyy listauksesta 1, joka kuvaa typpilannoitusta vesialueiden lähistöllä, sekä kaltevilla alueilla rajoittavaa viljelysääntöä. Säännössä käytetään käsitetason termejä, kuten agrovoc:FertiliserApplication, joka kuvaa lannoitusoperaatiosta kerättyä (paikka)tietoa. On tärkeää huomata, että vaikka sääntö edellyttää kohtuullisen paljon tietoa, niin läheskään kaikkea tästä tiedosta ei välttämättä tarvita säännön konepäättelyssä. Esimerkiksi, mikäli käytetyssä lannoitteessa ei ole merkittävästi typpeä, ei lannoitusoperaation muilla ominaisuuksilla ole merkitystä konepäättelyn lopputulokseen, eikä muuta tietoa tällöin tarvita.

Listing 1: Saksalainen viljelysääntö GeoRIF esitysmuodossa

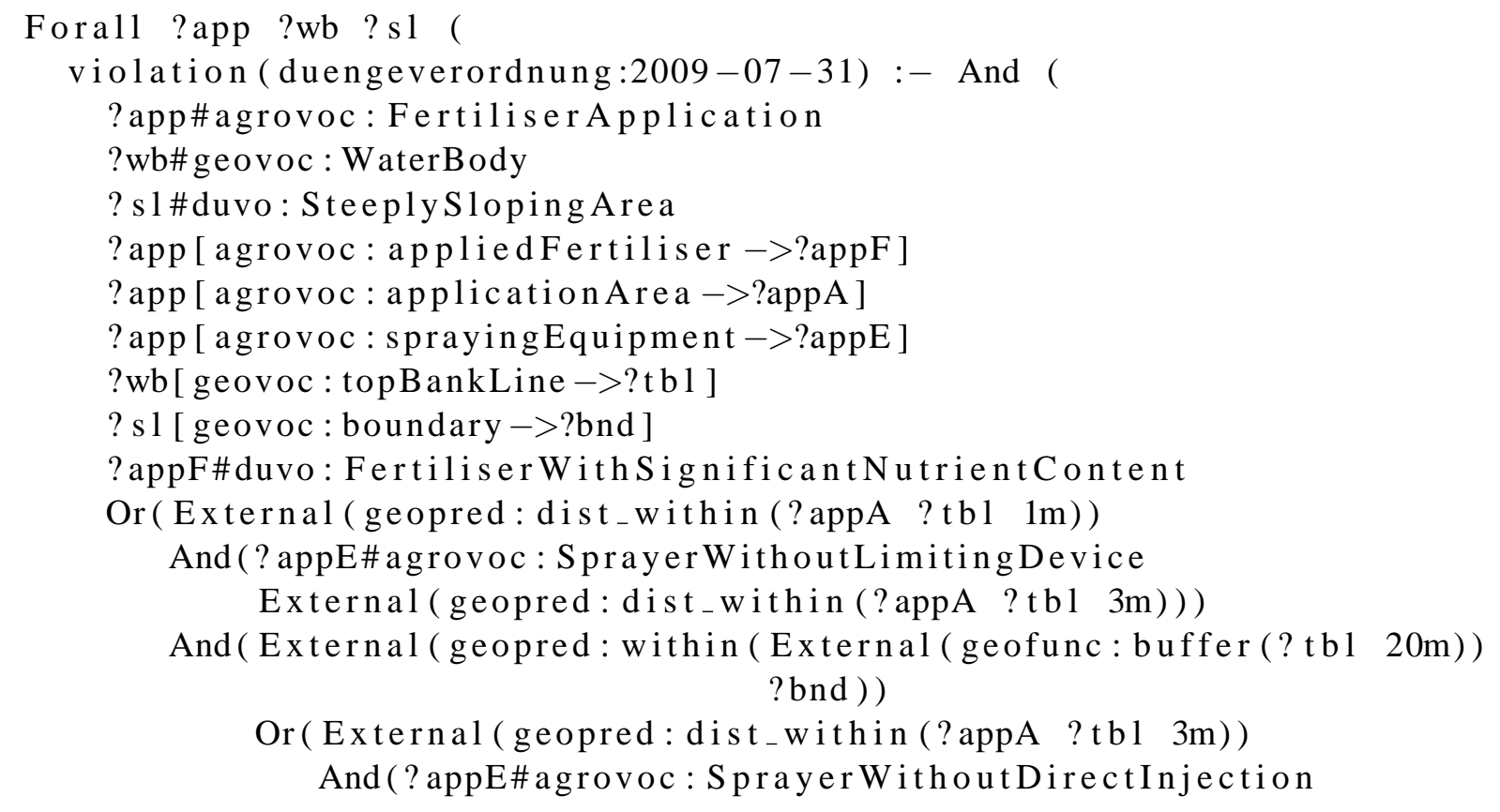

${ }^{1}$ 2009-2011 www . futurefarm.eu 


\section{External( geopred:dist_within(?appA ?tbl 10m))))))))}

Lisäksi paikkatiedon oletettiin olevan XML-pohjaisessa GML2 esitysmuodossa[8], joka mahdollistaa paikkatiedon ja paikkatietoon liittyvän tiedon esityksen helposti konekäsiteltävässä muodossa. GML on lisäksi yleisesti hyvin tunnettu ja tuettu tiedostomuoto, jolle löytyy tuki lähes kaikista paikkatietoa käsittelevistä ohjelmistoista sekä kirjastoista. Muu kuin paikkatieto oletettiin ehkä hieman optimistisesti AgroXML esitysmuotoon[4], mutta koska tässä tutkimuksessa keskitytään paikkatiedon integraatioon, ei tällä oletuksella tai sen seurauksilla ole suurtakaan merkitystä.

Tutkimusalustana toimi niin ikään FutureFarm projektin puitteissa kehitetty ja kuvassa 1 esitetty REST-pohjainen[3] palveluarkkitehtuuri. Tämä palveluarkkitehtuuri on tarkoitettu viljelysääntöjen käsittelemiseen FMIS-järjestelmille ja sen keskeinen komponentti on konepäättelijä[7], joka on kuvassa nimellä päättelypalvelu. Konepäättelijä on tehty erityisesti GeoRIF esitysmuodon käsittelyyn ja sen paikkatietotoiminnallisuus perustuu OGC:n tarjoamaan yleisesti käytettyyn paikkatietokirjastoon. Muut palvelut arkkitehtuurissa ovat lähinnä viljelysääntöjen löytämiseen ja siirtämisen. Tutkimuksen tarkoituksena on tietointegraatio konepäättelijän toiminnan edellyttävien tietolähteiden ja GeoRIF esitettyjen sääntöjen välillä. Tähän tietointegraatioon käytetään tietämyspohjaisia menetelmiä, joissa apuna toimii Yhdistyneiden Kansakuntien ylläpitämä maatalouden käsitesanasto AGROVOC[10].

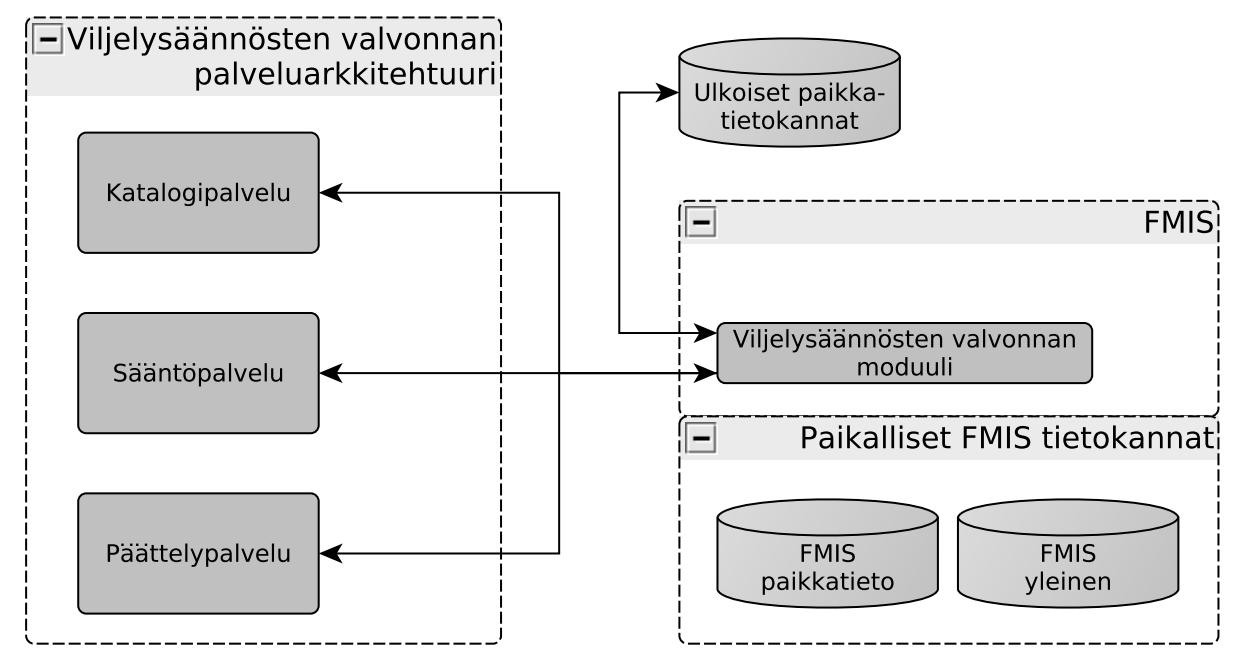

Kuva 1: Järjestelmän yleisarkkitehtuuri 


\section{Tulokset}

Sääntö GeoRIF-muodossa

Tieto GML2-muodossa

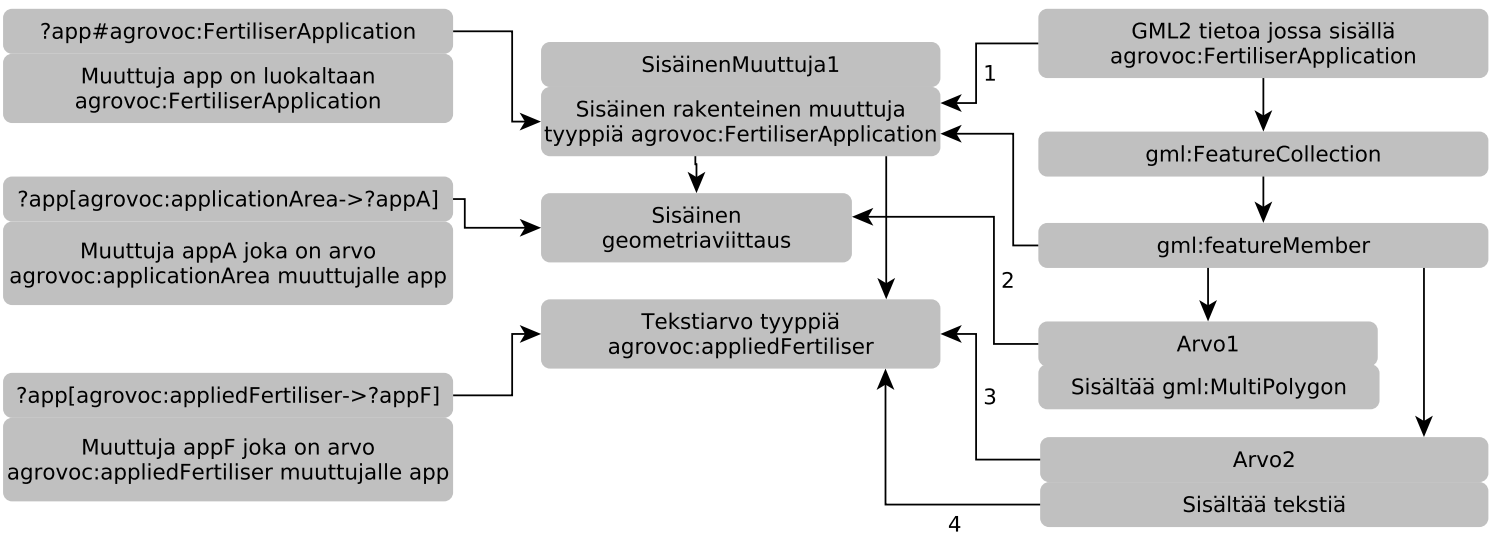

Kuva 2: Esimerkki tietointegraation toiminnasta

Esimerkki käsiteltävästä tietointegraatiotapauksesta on annettu kuvassa 2, siinä pyritään osittain integroimaan listauksessa 1 annetun säännön agrovoc:FertiliserApplication tietoelementti ja sen agrovoc:appliedFertiliser osa. Käytännössä tämä tietointegraatio jakautuu pienempiin osiin, jotka on kuvassa merkitty luvuilla yhdestä neljään konepäättelijän ja GML2-tietolähteen välille. Nämä tietointegraation osat ja niiden saavuttamiseen käytetyt tekniikat ovat:

1. tiedostotason integraatio on annettujen syötetiedostojen tai tietokokonaisuuksien yhdistäminen säännön päättelemisen vaatimiin tietolähteisiin. Tämä ei ole erityisen haastava tietointegraatio-ongelma, koska konepäättelijälle annetut syötetiedostot merkitään sillä AGROVOC tietokäsitteellä, jonka ne toteuttavat. Nämä vaaditut tietokäsitteet ovat jopa suoraan luettavissa GeoRIF muotoisista säännöistä, koska GeoRIF ja RIF esitysmuodot mahdollistavat muuttujien luokittelun Member-rakenteilla. Listauksen 1 esimerkkisäännössä nämä ovat ?app\#agrovoc:FertiliserApplication muotoiset lausekkeet, eli muuttuja app kuuluu tietoluokkaan agrovoc:FertiliserApplication. Toisinsanoen, säännön päättely edellyttää agrovoc:FertiliserApplication tietolähteen, jonka kaikki alkiot ovat mahdollisia arvoja muuttujalle app.

2. paikkatietoelementin integraatio tapahtuu pitkälti paikkatietoa käsittelevässä kirjastossa. Konepäättelijän on mahdollista selvittää helposti mikä osa GML2 rakenteesta gml : featureMember on varsinainen paikkatiedon geometria. Vertailut ja operaatiot tällä geometrialla tapahtuvat tämän jälkeen paikkatietokirjastossa, jolloin varsinaista geometriaa ei tarvitse erikseen muuntaa tai käsitellä konepäättelijässä.

3. muun tiedon integraatio vaatii joko sopivasti muotoillun GML2 tiedoston, jossa jokaisessa gml : featureMember elementissä on sitä vastaava tietokäsite, tai (käytännössä) vastaavan tiedon erillisenä kuvauksena tai ontologiana. Tähän soveltuu W3C:n standardoima OWL-kieli (Web Ontology Language). Mikäli kyseessä on selkeä 1:1 vastaavuus, on tietointegraatio suoritettavissa käyttämällä OWLkielen rajoittuneinta OWL Lite muotoa. Monimutkaisemmilla vastaavuuksilla tarvitaan joko ilmaisuvoimaisempaa muotoa OWL-kielestä tai kokonaan muita menetelmiä.

4. tietosisällön integraatio on työläin vaihe, joka valitettavasti on tehtävä enimmäkseen käsityönä. Tämä siksi, että automaattinen sisällönmuunnos vaatisi merkittävän määän oheistietoa, jota yleensä ei ole saatavilla tai jonka esittäminen olisi kohtuuttoman työlästä. 


\section{Johtopäätökset}

Tarkkuusviljelyn paikkatietointegraatio pysyy hankalana ongelmana, johon tuskin lähitulevaisuudessakaan saadaan yleistä ratkaisua. Yksittäisissä tapauksissa voidaan kuitenkin hyödyntää moderneja tietoteknisiä menetelmiä, joilla eri tietointegraation osa-alueet saadaan tietyillä lähtöoletuksilla suoritetuksi. Erityisen merkitsevänä tekijänä tietointegraation onnistumiselle voidaan pitää tietolähteiden ominaisuuksia. Esimerkiksi juuri RIF ja GML2 mahdollistavat oheistiedon liittämisen dokumentteihin, sekä käsitetason abstraktion.

\section{Viitteet}

[1] Harold Boley, Michael Kifer, Paula-Lavinia Pätranjan, and Axel Polleres. Rule interchange on the web. In Grigoris Antoniou, Uwe Aßmann, Cristina Baroglio, Stefan Decker, Nicola Henze, PaulaLavinia Patranjan, and Robert Tolksdorf, editors, Reasoning Web, volume 4636 of Lecture Notes in Computer Science, pages 269-309. Springer Berlin / Heidelberg, 2007.

[2] Jan de Graaff, Aad Kessler, and Filomena Duarte. Financial consequences of cross-compliance and flat-rate-per-ha subsidies: The case of olive farmers on sloping land. Land Use Policy, 28(2):388 394, 2011.

[3] Roy Thomas Fielding. Architectural Styles and the Design of Network-based Software Architectures. $\mathrm{PhD}$ thesis, University of California, Irvine, Irvine, California, 2000.

[4] M. Kunisch, J. Frisch, D. Martini, and S. Böttinger. agroxml—a standardized language for data exchange in agriculture. In Proceedings of 6th Biennial Conference of European Federation of IT in Agriculture Glasgow, 2007.

[5] Edward Nash, Jens Wiebensohn, Raimo Nikkilä, Anna Vatsanidou, Spyros Fountas, and Ralf Bill. Towards automated compliance checking based on a formal representation of agricultural production standards. Computers and Electronics in Agriculture, (Accepted by Editor), 2011.

[6] Edward Nash, Jens Wiebensohn, Raimo Nikkilä, Anna Vatsanidou, Spyros Fountas, and Ralf Bill. Towards automated compliance checking based on a formal representation of agricultural production standards. Computers and Electronics in Agriculture, 78(1):28 - 37, 2011.

[7] Raimo Nikkilä, Jens Wiebensohn, Edward Nash, Ilkka Seilonen, and Kari Koskinen. A service infrastructure for the representation, discovery, distribution and evaluation of agricultural production standards for automated compliance control. Computers and Electronics in Agriculture, 80(0):80 88, 2012.

[8] OpenGIS, Cox, S., Cuthberg, A., Lake, R., Martell, R. (ed.). Geography Markup Language (GML) v2.0. Document number 01-029, 2001.

[9] C.G. Sørensen, S. Fountas, E. Nash, L. Pesonen, D. Bochtis, S.M. Pedersen, B. Basso, and S.B. Blackmore. Conceptual model of a future farm management information system. Computers and Electronics in Agriculture, 72(1):37 - 47, 2010.

[10] United Nations. AGROVOC Multilingual Agricultural Thesaurus. ICTUpdate, May 2005.

[11] C Varela-Ortega and J Calatrava. 2004. evaluation of cross compliance: Perspectives and implementation, report of seminar 4. In The Oxford Handbook of Public Policy, pages 109-123. University Press, 2004. 